\title{
Should assisted dying for psychiatric disorders be legalized in Canada?
}

\author{
Scott Y.H. Kim MD PhD, Trudo Lemmens LLM DCL
}

$\mathrm{T}$ he Supreme Court of Canada ruled in Carter v. Canada ${ }^{1}$ that competent, consenting adults whose suffering is due to a "grievous and irremediable" medical condition should have access to some form of medical assistance in dying and invited Parliament to develop a regulatory regime along these "parameters." The Parliamentary Special Joint Committee on Physician-Assisted Dying suggested that the "grievous and irremediable" criterion includes nonterminal medical conditions, including psychiatric disorders. ${ }^{2}$ The federal government's Bill C-14, on the other hand, defined "grievous and irremediable" as an "advanced state of irreversible decline in capabilities" in a person for whom "natural death has become reasonably foreseeable." "The Senate ultimately passed the bill, despite initially voting to remove the requirement for reasonably foreseeable death. ${ }^{4}$ The new law does not discriminate among people near death based on their disorder or disability, psychiatric or otherwise; however, assisted dying because of a psychiatric disorder would not fulfill the access criteria. The passing of the bill may not, however, put to rest the debate over whether psychiatric disorders could qualify as eligible conditions for assisted dying, and the government has indicated it will be studying the issue.

Arguments for including mental illness as an eligible condition for assisted dying almost always focus on severe depression. The assumption is that doctors can accurately determine medical futility and decisional capacity, with the implication that no ineligible person would receive assisted death. However, evidence suggests this focus is too narrow and fails to consider real threats to patients with mental illness.

If assisted dying is legalized for patients with psychiatric conditions, it will not be just for severe, refractory depression. In Belgium and the Netherlands, medical assistance in dying has been provided to people with chronic schizophrenia, posttraumatic stress disorder, severe eating disorders, autism, personality disorders and even prolonged grief. ${ }^{5,6}$ Women are more than twice as likely as men to request $t^{4}$ and receive $\mathrm{e}^{5}$ assisted dying for psychiatric disorders, but we do not know why. Most people who request it for such reasons have characteristics that compromise their ability to cope with adversity, including personality disorders and social disconnection. ${ }^{6}$ Discussions, much less evidence-based guidance, of how to evaluate people who request assisted dying because of prolonged grief, autism, schizophrenia or personality disorders are lacking.

Furthermore, the key eligibility criterion of "irremediable" condition is inherently vague and unreliable, even when applied to the types of severe cases usually mentioned by those who advocate for including psychiatric disorders in the legislation for assisted dying. Consider a patient who has been suffering from chronic depression for 20 years, has tried more than a dozen different medications as well as electroconvulsive therapy and is currently in a depressive episode that has lasted several years. Based on published cases in Belgium ${ }^{5}$ and the Netherlands, ${ }^{6}$ such a patient would likely be deemed to meet the "irremediable" criterion. However, evidence suggests that most such patients can achieve remission if given high-quality treatment. ${ }^{7}$

The Parliamentary Special Joint Committee on Physician-Assisted Dying's recommendation that "irremediable ... does not require the patient to undertake treatments that are not acceptable to the individual" could be particularly consequential for patients with psychiatric conditions. It is one thing for a patient with a terminal illness to
Competing interests: None declared.

This article has been peer reviewed.

Correspondence to: Scott Kim, scott.kim@nih.gov

CMAJ 2016. DOI:10.1503 /cmaj.160365 
refuse a last-ditch effort, but quite another to set aside a core clinical imperative in psychiatric treatment: compassionately and skillfully helping patients even through periods of sustained suffering during which people often lose the will to live and despair about whether things will get better. A review of 66 case summaries of euthanasia published by Dutch regional euthanasia review committees found that most patients who received assisted dying for a psychiatric condition were deemed to have met the criterion while refusing recommended treatments; many likely did not receive all indicated treatments. ${ }^{6}$ In fact, judgments of medical futility vary between physicians; in the Netherlands study, physicians disagreed about medical futility in almost a quarter of the cases. ${ }^{6}$ In a case series, a psychiatrist assessed 100 consecutive cases of Belgian patients with psychiatric conditions who requested assisted dying; ${ }^{5}$ all 100 patients were deemed have "no prospect of improvement" due to "treatment resistance," which suggests vagueness of the applied criterion.

A further concern is that some patients who request assisted dying because of a psychiatric illness may not meet the criteria for mental capacity. ${ }^{8}$ Although psychiatric diagnoses should not be equated with incapacity, some conditions (e.g., psychotic illnesses, neurocognitive disorders, severe depression, anorexia nervosa and intellectual disability) may increase the risk of incapacity. Evaluating capacity involves applying broad criteria to complex clinical situations. In a survey of consultant psychiatrists, most reported that they find assessment of decision-making capacity to be a challenging task, and training in capacity evaluations was seen as suboptimal. ${ }^{9}$ To minimize bias and error, especially when the consequence could be premature death, assessments of decision-making capacity need to include rigorous thresholds with carefully articulated justifications. Evidence, however, indicates that this is not necessarily the case. In our review of 66 case summaries in the Netherlands (unpublished data), the capacity determination in most cases was reported as a simple global judgment of capacity, even for patients with disorders that increase the risk of incapacity. In 8 of the 66 cases, physicians disagreed about the patient's capacity status. ${ }^{6}$ In the case series from Belgium, ${ }^{5}$ the psychiatrist deemed all 100 patients who requested assisted dying for psychiatric conditions (14 of whom had psychotic disorders) "capable," which raises the question of whether a rigorous threshold for capacity was used.

Importantly, the Parliamentary Special Joint Committee also recommended that a prior review system by a panel or judge be prohibited, and it suggested that a retrospective review system would be sufficient. However, it is worth noting that the Belgian and Dutch euthanasia review bodies almost never find that doctors have breached the due care criteria; the Belgian review commission found that only 1 out of more than 10000 reported euthanasia cases failed to meet the criteria. ${ }^{10}$ It seems improbable that doctors virtually never make a mistake when it comes to eligibility evaluations for assisted dying; it is more likely that broad and vague criteria make it difficult to hold doctors accountable.

In a survey of health care professionals and members of the general public in the Netherlands, only $28 \%$ of the public and 1 out of 3 health professionals approved of it for patients with psychiatric disorders. ${ }^{11}$ In a recent public opinion poll of 1517 Canadians, only 22\% supported legalizing assisted dying for psychological suffering. ${ }^{12}$ But the pool of people who might request it because of a psychiatric disorder is potentially large, and the number who have requested and received it for such reasons in the countries that allow it appears to be on the rise. ${ }^{6,10}$ Because the Parliamentary Special Joint Committee recommends that, eventually, competent mature minors should be eligible for assisted dying, even those with a psychiatric condition (a practice that even the liberal Belgian regime forbids), it is conceivable that without clear wording in Bill C-14, young people struggling with psychological issues could be eligible for assisted dying.

We believe there is a serious gap between the idealized basis upon which assisted dying for patients with psychiatric conditions is advocated and the reality of its practice, as reflected in evidence from Belgium and the Netherlands. A policy for access to assisted dying by nonterminally ill patients with psychiatric conditions will put many vulnerable and stigmatized people at risk. Perhaps those who advocate for extending access to people with psychiatric disorders may be willing to tolerate a number of potentially avoidable premature deaths as acceptable because access to assisted dying is felt to be so important in principle. However, that argument must be made explicit and debated publicly.

\section{References}

1. Carter v. Canada (Attorney General) 2015 SCC 5. Available: https://scc-csc.lexum.com/scc-csc/scc-csc/en/item/14637/index.do (accessed 2015 Sept. 9).

2. Report of the Special Joint Committee on Physician-Assisted Dying. Medical assistance in dying: a patient-centred approach. Ottawa: Parliament of Canada; 2016 Feb 25. Available: www.parl. gc.ca/Committees/en/PDAM?parl=42\&session=1 (accessed 2016 Mar. 1).

3. Canada. An Act to amend the Criminal Code and to make related amendments to other Acts (medical assistance in dying), 2016, Bill C-14, 1st reading, Apr. 14, 2016 (42nd Parliament, 
1st session). Available: www.parl.gc.ca/HousePublications/ Publication. asp ? Language $=E \&$ Mode $=1 \&$ DocId $=8183660(\mathrm{ac}-$ cessed 2016 Apr. 14)

4. Tunney C. Liberals' assisted-dying bill is now law after clearing final hurdles. CBC News 2016 June 17. Available: www.cbc.ca/ news/politics/assisted-dying-bill-senate-approval-1.3640195 (accessed 2016 June 17).

5. Thienpont L, Verhofstadt M, Van Loon T, et al. Euthanasia requests, procedures and outcomes for 100 Belgian patients suffering from psychiatric disorders: a retrospective, descriptive study. BMJ Open 2015;5:e007454.

6. Kim SYH, De Vries RG, Peteet JR. Euthanasia and assisted suicide of patients with psychiatric disorders in the Netherlands 2011 to 2014. JAMA Psychiatry 2016;73:362-8.

7. Fekadu A, Rane LJ, Wooderson SC, et al. Prediction of longerterm outcome of treatment-resistant depression in tertiary care. Br J Psychiatry 2012;201:369-75.

8. Price A. Mental capacity as a safeguard in assisted dying: Clarity is needed. BMJ 2015;351:h4461.

9. Seyfried L, Ryan KA, Kim SY. Assessment of decision-making capacity: views and experiences of consultation psychiatrists. Psychosomatics 2013;54:115-23.

10. Lemmens T. The conflict between open-ended access to physician-assisted dying and the protection of the vulnerable: lessons from Belgium's euthanasia regime for the Canadian post-Carter era. In: Régis C, Khoury L, Kouri RP, editors. Les grands conflits en droit de la santé. Cowansville (QC): Éditions Yvon Blais; 2016:261-317.
11. Kouwenhoven PS, Raijmakers NJ, van Delden JJ, et al. Opinions of health care professionals and the public after eight year of euthanasia legislation in the Netherlands: a mixed methods approach. Palliat Med 2013;27:273-80.

12. Physician-assisted suicide: Canadians reject certain Commons committee recommendations. Vancouver: Angus Reid Institute; 2016. Available: http://angusreid.org/assisted-suicide-law (accessed 2016 Apr. 7).

Affiliations: Department of Bioethics (Kim), National Institutes of Health, Bethesda, Md.; Faculty of Law and Dalla Lana School of Public Health (Lemmens), University of Toronto, Toronto, Ont.

Contributors: Both authors contributed substantially to the concept of the article, and the analysis and interpretation of data; drafted or revised the manuscript critically for important intellectual content; approved the final version to be published; and agreed to act as guarantors of the work.

Disclaimer: The opinions expressed in this article are those of the authors and do not represent the views or policies of the National Institutes of Health, the Department of Health and Human Services, or the US government.

Acknowledgement: The authors thank Samuel Kerstein for helpful comments on an earlier draft. 